\section{Commentary: Adult support with a pulsatile VAD: Reawakening of a bygone era?}

\author{
James K. Kirklin, MD
}

Bartfay and colleagues ${ }^{1}$ in Gothenburg, Sweden, present an analysis of the Berlin Heart EXCOR pulsatile extracorporeal mechanical circulatory support (MCS) device in a combined pediatric and adult population. Of course, the US experience with this device is extensive in infants and children with single or biventricular failure. ${ }^{2}$ The Berlin Heart radically changed the landscape of pediatric MCS with its introduction in the United States in 2000 and eventual Food and Drug Administration approval in 2011, becoming the only reliable source of longer term support for infants and small children and bridging thousands of young patients to heart transplantation.

The unique and important aspect of the report by Bartfay and colleagues ${ }^{1}$ is the analyzed application of this device in adults. The authors emphasize two major indications for the Berlin EXCOR in their practice in Sweden: complex congenital heart disease (CHD) and planned biventricular assist device (BVAD) support.

In patients with $\mathrm{CHD}$, the potential for atrial cannulation is an advantage of the Berlin Heart when the available sites for ventricular cannulation (in particular, with a systemic morphologic right ventricle) are considered by the surgeon to be at high risk of inflow obstruction with a standard continuous flow (CF) device. However, good outcomes have been reported with support of a systemic right ventricle using CF pumps. ${ }^{3}$ A US Interagency Registry for Mechanically Assisted Circulatory Support analysis of CF devices in adults with CHD revealed survival with the

From the Division of Cardiothoracic Surgery, Department of Surgery, Kirklin Institute for Research in Surgical Outcomes, University of Alabama at Birmingham, Birmingham, Ala.

Disclosures: I receive partial salary paid to my institution for my role as Director of Data and Clinical Center for Society of Thoracic Surgeons Interagency Registry for Mechanically Assisted Circulatory Support.

The Journal policy requires editors and reviewers to disclose conflicts of interest and to decline handling or reviewing manuscripts for which they may have a conflict of interest. The editors and reviewers of this article have no conflicts of interest.

Received for publication April 27, 2020; revisions received April 27, 2020; accepted for publication April 29, 2020; available ahead of print May 15, 2020.

Address for reprints: James K. Kirklin, MD, Division of Cardiothoracic Surgery, Department of Surgery, Kirklin Institute for Research in Surgical Outcomes, University of Alabama at Birmingham, ZRB 739, 703 19th St South, Birmingham, AL 35294 (E-mail: jkirklin@uabmc.edu).

J Thorac Cardiovasc Surg 2021;161:1465-6

$0022-5223 / \$ 36.00$

Copyright (c) 2020 by The American Association for Thoracic Surgery

http://dx.doi.org/10.1016/j.jtcvs.2020.04.157

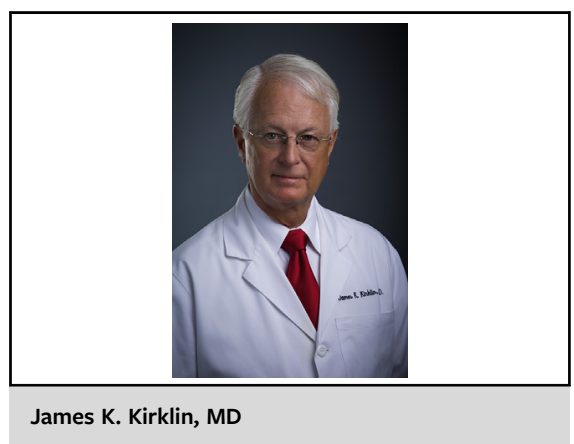

CENTRAL MESSAGE

Adult biventricular mechanical circulatory support with pulsatile devices may improve outcomes.

device of $\sim 70 \%$ at 1 year, $10 \%$ less than that for nonCHD patients. ${ }^{4}$ Thus, in unusual circumstances, the surgical armamentarium for adults with complex CHD could incorporate this device for isolated systemic ventricular support.

Planned BVAD support as a bridge to recovery or a transplantation strategy in adults appears to be the major area of opportunity for the Berlin EXCOR. This configuration is frequently used by congenital heart surgeons for infants and small children. Of the current options for biventricular support in the United States, the reported 1-year survival for BVADs (with a CF pump on the left side; $<60 \%)^{5}$ and total artificial heart $(\sim 50 \%)^{6}$ has lagged considerably behind isolated left ventricular support. ${ }^{5}$ Although not risk adjusted compared with US centers, the Kaplan-Meier 1-year survival of nearly $80 \%$ for biventricular support with 2 paracorporeal Berlin Heart pulsatile pumps, as reported by the authors, ${ }^{1}$ is impressive.

With the potential advantages (although not without debate) of pulsatile flow, the simplicity of implantation, and the potential for hospital discharge in Sweden, this pump has performed well in the adult biventricular configuration, albeit with the known susceptibility to embolic strokes. The major caveat in assessing the Swedish experience is the relatively short wait times for transplantation, which is currently not the case in the United States. For this to be a truly viable option in the United States, the pump could be used in an "off-label" application, with an elevated priority for organ allocation assigned on the basis of BVAD support without hospital discharge (as in the US pediatric application).

Thus, for all that pediatric surgeons have learned from their adult colleagues in the application of CF pumps in pediatric patients, perhaps this is an opportunity for those experienced with the pediatric Berlin EXCOR to return the favor 
and share their knowledge with adult MCS surgeons, adding an important BVAD option for the adult MCS team.

\footnotetext{
References

1. Bartfay S-E, Dellgren G, Hallhagen S, Wåhlander H, Dahlberg P, Redfors B, et al. Durable circulatory support with a paracorporeal device as an option for pediatric and adult heart failure patients. J Thorac Cardiovasc Surg. 2021;161:1453-64.e4.

2. Morales DLS, Rossano JW, VanderPluym C, Lorts A, Cantor R, St Louis JD, et al; Pedimacs Investigators. Third annual pediatric interagency registry for mechanical circulatory support (pedimacs) report: preimplant characteristics and outcomes. Ann Thorac Surg. 2019;107:993-1004.
}

3. Kirov H, Faerber G, Doenst T. Implantation of a HeartMate 3 left ventricular assist device in a patient with congenitally corrected transposition of the great arteries. $J$ Heart Lung Transplant. 2019;38:S370.

4. Cedars A, Vanderpluym C, Koehl D, Cantor R, Kutty S, Kirklin JK. An interagency registry for mechanically assisted circulatory support (INTERMACS) analysis of hospitalization, functional status, and mortality after mechanical circulatory support in adults with congenital heart disease. J Heart Lung Transplant. 2018;37:619-30.

5. Kirklin JK, Xie R, Cowger J, de By TMMH, Nakatani T, Schueler S, et al. Second annual report from the ISHLT mechanically assisted circulatory support registry. $J$ Heart Lung Transplant. 2018;37:685-91

6. Arabía FA, Cantor RS, Koehl DA, Kasirajan V, Gregoric I, Moriguchi JD, et al. Interagency registry for mechanically assisted circulatory support report on the total artificial heart. J Heart Lung Transplant. 2018;37:1304-12.
See Article page 1453.

\section{Commentary: Rejuvenation of a trusted tool}

\author{
Chet R. Villa, MD, and David L. S. Morales, MD
}

Axial and centrifugal continuous-flow (cf) ventricular assist devices (VADs) rapidly supplanted pulsatile VADs as the devices of choice for adults in the mid-to-late 2000s. Although the field has largely consolidated toward the use of cfVADs in large patients requiring left ventricular support alone, the anatomic challenges of cfVAD implantation in children (generally $<20 \mathrm{~kg}$ ), certain adults with congenital heart disease, and patients requiring biventricular support require a more individualized approach.

In the current issue of the Journal, Bartfay and colleagues ${ }^{1}$ describe the use of the EXCOR (Berlin Heart, Inc, The Woodlands, Tex) in these populations. The overall outcomes are good and underscore the fact that the EXCOR performs quite well in appropriately selected

\footnotetext{
From the Heart Institute, Cincinnati Children's Hospital Medical Center, Cincinnati, Ohio.

Disclosures: Dr Morales is a consultant for Berlin Heart, Medtronic, Abbott, and SynCardia. Dr Villa reported no conflicts of interest.

The Journal policy requires editors and reviewers to disclose conflicts of interest and to decline handling or reviewing manuscripts for which they may have a conflict of interest. The editors and reviewers of this article have no conflicts of interest.

Received for publication May 7, 2020; revisions received May 7, 2020; accepted for publication May 11, 2020; available ahead of print May 25, 2020.

Address for reprints: David L. S. Morales, MD, The Heart Institute at Cincinnati Children's Hospital Medical Center, 3333 Burnet Ave, MLC 2004, Cincinnati, OH 45229 (E-mail: David.Morales@cchmc.org).

J Thorac Cardiovasc Surg 2021;161:1466-7

$0022-5223 / \$ 36.00$

Copyright (c) 2020 by The American Association for Thoracic Surgery

http://dx.doi.org/10.1016/j.jtcvs.2020.05.039
}

\section{Check for updates}

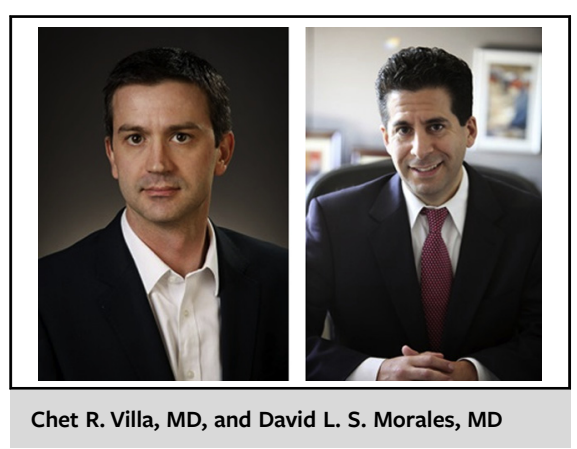

CENTRAL MESSAGE

Patient selection remains fundamental to outcomes even as the VAD armamentarium expands and evolves.

patients. These data are especially notable when considering the current study also depicts feasibility and utility of discharge on the EXCOR with the mobile driving unit. The study is consistent with overall outcomes within the field showing improved outcomes in the current era as patient selection and anticoagulation evolve and centers garner more experience. ${ }^{2,3}$ However, a more in-depth examination of the use of the device by the authors in a biventricular assist device (BiVAD) configuration is warranted. The current results are notably better than the larger experience within the field, where BiVAD support has a 6 -month survival of $\sim 65 \% .{ }^{4}$ This difference in outcome is likely a function of patient characteristics as well as a very liberal approach to the use of BiVAD support based on preoperative right ventricular function. 